\title{
Rat strain differences in pilocarpine-induced mouse killing
}

\author{
PATRICIA E. GAY \\ Camden College of Arts and Sciences, Rutgers University, Camden, New Jersey 08102
}

and

\author{
RUSSELL C. LEAF \\ Rutgers College, Rutgers University, New Brunswick, New Jersey 08901
}

\begin{abstract}
Repeated injections of pilocarpine induced mouse killing in both Holtzman and Long-Evans strain rats. Higher drug doses (15-30 mg/kg), however, were required to initiate killing in the Long-Evans animals, but this strain showed rapid onset of killing and continued to kill when given vehicle alone. Repeated injections of arecoline failed to initiate killing.
\end{abstract}

Repeated injections of pilocarpine initiate prey killing by Holtzman-strain rats that do not kill spontaneously (McCarthy, 1966; Vogel \& Leaf, 1972; Wnek \& Leaf, 1973). Such killing is blocked by low doses of centrally active anticholingergic drugs, but is facilitated or unaffected by similar doses of their less centrally active quaternary analogues (Vogel \& Leaf, 1972; Wnek \& Leaf, 1973). Pilocarpine-induced killing is morphologically similar to spontaneous killing (Wnek \& Leaf, 1973), and it does not seem to be due to changes in physiological systems that regulate feeding (Gay, Leaf, \& Arble, 1975; Overstreet, Hadick, \& Russell, 1972; Gay, Cole, \& Leaf, Note 1; Gay \& Leaf, Note 2). These findings, taken together, suggest that such killing may be due to a selective action of the drug on brain systems that developed at an early stage in the evolution of mammals specifically to regulate predatory behavior. Pilocarpine does not appear to initiate killing in other rodent species with brains similar to those of the rat, however. Studies with hamsters and guinea pigs (Wnek \& Leaf, 1973) and with grasshopper mice (Gay and Leaf, unpublished observations) have produced uniformly negative results. These latter, negative, findings have called into question the notion that pilocarpine induces prey killing by acting on a basic natural system (similar to the systems involved in feeding, drinking, or sexual behavior), with similar properties in related species and with a very ancient evolutionary history. As a consequence, it seemed

This research was supported by USPHS Grant MH21247 to Russell C. Leaf and Patricia E. Gay, Principal Investigators, and by gifts of equipment and supplies from the Squibb Institute for Medical Research. The experiments reported here formed part of a dissertation submitted by the first author to the Graduate Faculty of Rutgers University in partial fulfillment of the requirements of the degree of Doctor of Philosophy. We are indebted to Eileen Hendrickson, Betty Wilensky Mayer, John A. Consalvi, Jr., and Mario Rivera for technical assistance throughout the course of the research. Requests for reprints should be sent to Patricia E. Gay, Department of Psychology, Rutgers University, Camden, New Jersey 08102. desirable to determine to what extent, among rats, the positive findings might be unique to the particular strain chosen for previous studies.

\section{EXPERIMENT I}

An initial study compared both male and female Long-Evans strain rats to male and female Holtzman strain rats. Because social isolation has been reported to interact with some forms of drug-induced mouse killing by rats (Ueki, Fujuvara, \& Ogawa, 1972; Valzelli \& Bernasconi, 1971), even though this has not been apparent with pilocarpine-induced killing in Holtzman-strain rats (Wnek \& Leaf, 1973), the effects of social isolation were examined in both sexes and strains tested.

\section{Method}

Subjects. The subjects were 24 adult male Holtzman albino rats, 24 adult female Holtzman albino rats, 24 adult male Long-Evans hooded rats, and 26 adult female Long-Evans hooded rats. The animals were all conceived, born, and raised in our laboratory and had been housed since weaning under crowded conditions (approximately two per single cage, four per double cage, or six per triple cage) in a colony room free of mice or mouse odors. All animals selected for study failed to kill a single mouse on a 30-min pretest for spontaneous mouse killing. A 30 -min pretest was used to select out spontaneous killers, because, in previous studies (Gay, Leaf, \& Arble, 1975; unpublished observations), a test of this duration was as successful in identifying reliable killers as a longer test period. The animals were approximately 120 days old at the time of drug testing.

The prey were adult ICR mice of both sexes.

Apparatus and Procedure. During testing, the rats were individually housed in stainless steel cages, in a room which also housed the mice used as prey. The mice were housed in groups in plastic cages on cedar shavings. All animals had ad-lib access to food and water, except during tests, when water bottles were removed to prevent pilocarpine-induced drinking from interfering with killing.

At the beginning of the experiment, all rats were housed individually and pretested for mouse killing. Animals of each sex and strain were then randomly assigned to one of two housing conditions. Animals in the non-isolation-adapted group began tests for pilocarpine-induced killing the day after they were placed in individual cages. Animals in the isolation-adapted group were 
allowed 4 ueeks in the mouse-free colony to adapt to the new caging conditions before pilocarpine tests began. Then, on the day before the beginning of pilocarpine testing, these animals were transferred. in their home cages, to the test room where they lived until the end of the experiment. Each rat was retested once for spontaneous mouse killing (30-min test) on the day before drug tests were begun.

Social isolation induced killing by two female Long-Evans rats, so only 24 of these animals completed the study. In addition, one male and one female Holtzman rat were eliminated during the course of the study because they became ill.

On each test day, each rat was injected with $7.5 \mathrm{mg} / \mathrm{kg}$ pilocarpine $\mathrm{HCl}$ in $1 \mathrm{cc} / \mathrm{kg} 0.9 \% \mathrm{NaCl}$ (pilocarpine) IP. Fifteen minutes later, a single mouse was introduced into the rat's home cage. Each rat was permitted $2 \mathrm{~h}$ to kill. Tests were continued for 12 consecutive days, or until one kill had occurred.

\section{Results and Discussion}

Adaptation to single housing did not prove to be a significant variable, as can be seen in Table 1 . Of the 48 animals in the non-isolation-adapted group, 11 killed within 12 tests, while of the 46 animals in the isolation-adapted group, 15 killed within the same time period. This difference between groups was not statistically significant $\left(\mathrm{df}=1, \chi^{2}=0.67, \dot{\mathrm{p}}<.30\right)$. These results support those of Wnek and Leaf (1973) and suggest that social isolation has, at most, a weak effect on pilocarpine-induced killing. While social isolation did induce spontaneous killing in two female Long-Evans rats, it had no significant effect on pilocarpine-induced killing. Thus, the ineffectiveness of the isolation in this study may depend on the strains tested, or on the use of pilocarpine, or on both. In other studies, isolation has facilitated killing induced by delta ${ }^{9}$-tetrahydrocannabinol and chlordiazepoxide in other rat strains (Ueki et al., 1972; Valzelli \& Bernasconi, 1971).

Figure 1 illustrates the cumulative percentage of rats of each sex and strain that killed mice on each test day. By Day 12, a significantly larger number of Holtzman than of Long-Evans rats had killed mice (df $=1, \chi^{2}=16.39, \mathrm{p}<.01$ ), but the more frequent killing by males than by females only approached significance $\left(\mathrm{df}=1, \chi^{2}=1.91, \mathrm{p}<.10\right)$. Both sexes of Long-Evans rats had very low rates $(8 \%)$ of killing. In addition, the Long-Evans animals seemed less affected by the peripheral effects of pilocarpine; they showed less urination, defecation, salivation, and lacrimation than did the Holtzman animals. Because the Long-Evans rats showed fewer observable effects of pilocarpine, it seemed possible that this strain might have a higher drug threshold for pilocarpine than the Holtzman strain.

\section{EXPERIMENT II}

Strain differences in drug responsivity seemed the most plausible explanation of the ineffectiveness of pilocarpine in inducing mouse killing in Long-Evans rats. Therefore, the effect of higher doses of pilocarpine on mouse killing in these animals was examined.
Table 1

Number of Rats Killing Mice During 12 Days of Pilocarpine Injections Under Conditions of Adaptation and Nonadaptation to Isolation

\begin{tabular}{llcc}
\hline & & Males & Females \\
\hline \multirow{2}{*}{ Holtzman Strain } & Isolation-Adapted & $7 / 11$ & $5 / 11$ \\
& Nonisolation-Adapted & $7 / 12$ & $3 / 12$ \\
\multirow{2}{*}{ Long-Evans Strain } & Isolation-Adapted & $2 / 12$ & $1 / 12$ \\
& Nonisolation-Adapted & $0 / 12$ & $1 / 12$ \\
\hline
\end{tabular}

\section{Method}

Subjects. The subjects were 40 adult male Long-Evans rats $(180-522 \mathrm{~g})$ and 40 adult female Long-Evans rats $(192-330 \mathrm{~g})$ that failed to kill a mouse during a 30 -min pretest for spontaneous mouse killing. They were selected from a larger population of 87 rats, of which 7 (6 males and 1 female) killed spontaneously. All animals were bred in our laboratory and had been housed since weaning under crowded conditions.

The prey were adult ICR-derived mice of both sexes.

Apparatus and Procedure. During testing, both rats and mice were housed and maintained as in Experiment $I$.

At the beginning of the experiment, all rats were housed in individual home cages, where all subsequent mouse-killing tests took place. They were then randomly assigned to four independent injection groups. Each injection group consisted of 10 male and $\mathbf{1 0}$ female rats that received one of the following doses of IP pilocarpine: $0.0,7.5,15.0$, or $30.0 \mathrm{mg} / \mathrm{kg}$. Pilocarpine injections were begun on the day following the pretest for spontaneous mouse killing, and the same dose was given daily for 12 days. On the 13th day, each rat received the vehicle alone. All injections were administered 15 min prior to a 2 -h test for mouse killing.

\section{Results and Discussion}

The results of Experiment II are shown in Figure 2 and Table 2.

Killing was induced in the Long-Evans rats with the higher pilocarpine doses. While $7.5 \mathrm{mg} / \mathrm{kg}$ did not induce reliably more killing than saline, 15.0 and $30.0 \mathrm{mg} / \mathrm{kg}$ produced a significant increase in the number of rats that killed mice (Fisher exact probability tests, $\mathrm{p}<.01)$. More rats killed mice with $30.0 \mathrm{mg} / \mathrm{kg}$ than with $15.0 \mathrm{mg} / \mathrm{kg}$, but this difference was not statistically significant. Once an animal initiated killing, it usually continued to kill on all subsequent pilocarpine tests.

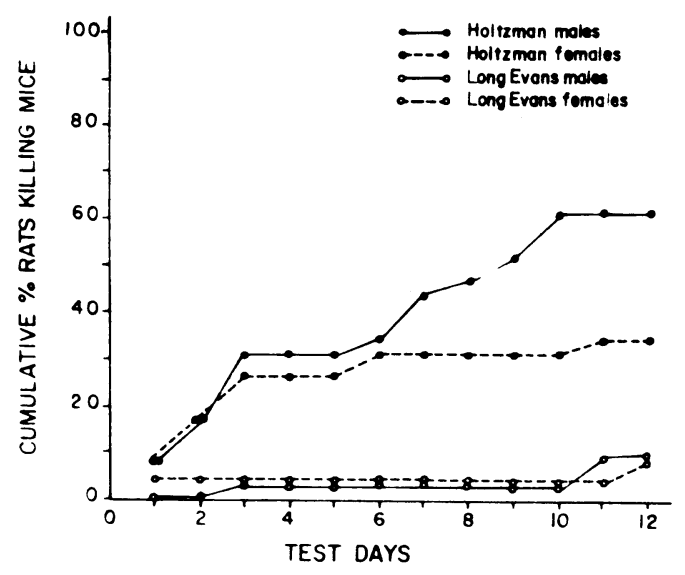

Figure 1. Cumulative percentage of rats induced to kill mice by daily injections of $7.5 \mathrm{mg} / \mathrm{kg}$ pilocarpine. 


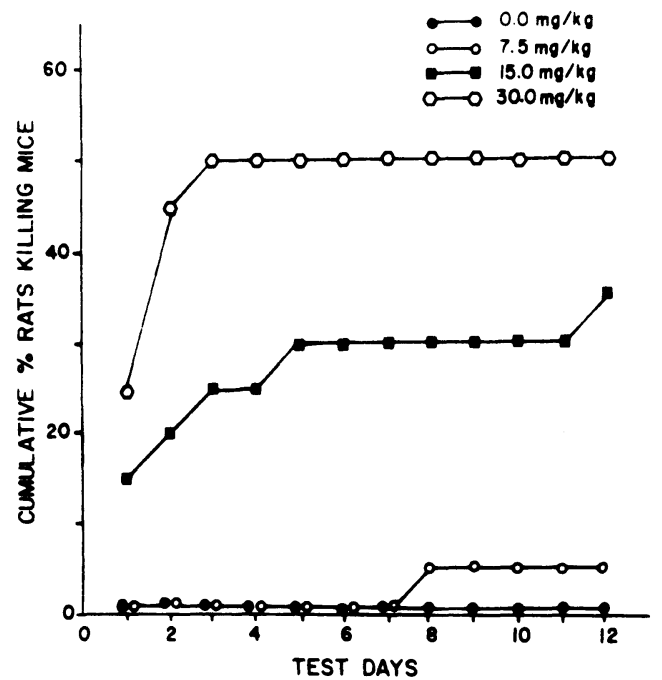

Figure 2. Cumulative percentage of Long-Evans rats killing mice as a function of test day. $\mathbf{N}=\mathbf{2 0}$ per dose group.

Although some hooded rats could be induced to kill mice with high doses of pilocarpine, the final percentage that killed (approximately $50 \%$ of the $30.0-\mathrm{mg} / \mathrm{kg}$ group) did not approach the value found for Holtzman albinos at the same dose $(90 \%-100 \%)$ (Vogel \& Leaf, 1972; Wnek \& Leaf, 1973). Thus, while pilocarpine induced killing in Long-Evans rats, these animals seemed less sensitive to this central effect of the drug than Holtzman rats. These animals were also less sensitive to observable peripheral effects of the drug, which may account for the large percentage of animals initiating killing following one of the first three injections ( $25 \%$ of all animals) compared to the percentage initiating killing after more than three injections (5\% of all animals). Wnek and Leaf (1973) have suggested that the gradual onset of killing with repeated doses of pilocarpine is partially due to habituation to the peripheral side effects of the drug. These data support their hypothesis by showing earlier onset of killing in animals less debilitated by side effects. In Holtzman rats, the onset of pilocarpine-induced killing is more gradual, even with high doses (Wnek \& Leaf, 1973).

One characteristic of pilocarpine-induced killing in Holtzman rats is that it is highly drug-state dependent (Gay, Leaf, \& Arble, 1975; Vogel \& Leaf, 1972; Wnek

Table 2

Number of Rats Killing Mice During 12 Days of Pilocarpine Injections by Sex and Dose Group*

\begin{tabular}{cccc}
\hline Dose $(\mathrm{mg} / \mathrm{kg})$ & Males & Females & Total \\
\hline .0 & 0 & 0 & 0 \\
7.5 & 1 & 0 & 1 \\
15.0 & 5 & 2 & 7 \\
30.0 & 6 & 4 & 10 \\
All Doses & 12 & 6 & 18 \\
\hline
\end{tabular}

${ }^{*} N=10$ per group
\& Leaf, 1973). Rats induced to kill with pilocarpine do not usually kill when subsequently given saline, or in a nondrugged state. In the present study, however. a relatively high percentage of Long-Evans rats that killed with pilocarpine, also killed when administered saline on the 13 th test day $(9 / 18$, with percentages within .dose groups approximately equal). The eventual independence of killing from the drug state may reflect a greater genetic propensity that Long-Evans rats have for spontaneous killing (Karli, Vergnes, \& Didiergeorges, 1969) and killing induced by brain manipulations (Lathan \& Thorne, 1974).

As in Experiment I, the more frequent killing by males than by females only approached statistical significance $\left(\mathrm{df}=1, \chi^{2}=2.18, \mathrm{p}<.10\right)$.

In summary, Long-Evans rats kill mice after repeated injections of pilocarpine. Their drug threshold, however, seems to be substantially higher than that of Holtzman rats, although they kill after fewer injections and continue to kill when tested without drug.

\section{EXPERIMENT III}

While nearly all Holtzman rats eventually kill mice after repeated injections of pilocarpine (Gay, 1973; Vogel \& Leaf, 1972; Wnek \& Leaf, 1973), other peripherally injected cholinergic drugs are generally ineffective in initiating mouse killing (Wnek \& Leaf, 1973). The reason for the ineffectiveness of other cholinomimetic drugs is not clear, but it could be related to the marked peripheral effects of such drugs in Holtzman rats. If this explanation were correct, and if Long-Evans rats are generally less sensitive to the peripheral effects of cholinergic agents, then other cholinomimetic drugs might induce killing in Long-Evans rats. The following study was designed to determine whether repeated injections of arecoline, the cholinomimetic alkaloid most similar to pilocarpine in its actions, could induce killing in Long-Evans rats.

\section{Method}

Subjects. The subjects were 15 adult, female Long-Evans rats $(230-280 \mathrm{~g})$ and 11 adult, male Long-Evans rats $(258-470 \mathrm{~g})$ that failed to kill mice on a 30 -min pretest. They were selected from a larger population of 27 rats (bred in our laboratory), of which 1 male killed spontaneously.

The prey were adult ICR-derived mice of both sexes.

Apparatus and Procedure. The animals were bred, housed, and maintained as in Experiment II.

At the beginning of the experiment, all rats were housed in individual home cages, where all subsequent mouse-killing tests took place. They were then randomly assigned to three independent dose groups. Each group consisted of four male and four or five female rats. Each rat in a group was administered IP one of the following doses of arecoline $\mathrm{HBr}$ in $1 \mathrm{cc} / \mathrm{kg} 0.9 \% \mathrm{NaCl}$ (arecoline): $0.0 \mathrm{mg} / \mathrm{kg}(\mathrm{N}=8), 3.75 \mathrm{mg} / \mathrm{kg}(\mathrm{N}=9)$, or $7.5 \mathrm{mg} / \mathrm{kg}(\mathrm{N}=9)$. Injections began the day following the pretest for spontaneous killing and the same dose was administered daily for 5 days. On the 6th day, all animals received $7.5 \mathrm{mg} / \mathrm{kg}$ pilocarpine to determine 
whether repeated doses of arecoline might "sensitize" animals to the actions of pilocarpine. On all trials, animals were injected with the appropriate drug $15 \mathrm{~min}$ prior to a 2 -h test for mouse killing.

\section{Results and Discussion}

The results of this study were clear and unambiguous. No rat killed from any treatment condition. Thus, like Holtzman rats (Wnek \& Leaf, 1973). Long-Evans rats are not easily induced to kill with arecoline. Previous treatment with arecoline also did not seem to facilitate pilocarpine induction of killing. The fact that no rat killed when administered pilocarpine, in contrast to the $8 \%$ rate observed in Experiments I and II, is not surprising. Vogel and Leaf (1972) and Wnek and Leaf (1973) have previously shown that habituation to mice during repeated testing reduces the rate of killing initiated with low doses of pilocarpine.

\section{GENERAL DISCUSSION}

Repeated injections of pilocarpine seem to initiate mouse killing in more than a single rat strain, although drug threshold and other parameters may vary. While the Long-Evans rats in these studies could be induced to kill with higher doses of pilocarpine, they differed from Holtzman rats in the rate of initiation of killing, in the final percentage induced to kill, and in the dependency of killing on the drug state. The rate of "spontaneous killing" also differs between rat strains (Galef, 1970; Karli, 1956; Karli et al., 1969), and strain differences in drug thresholds are not uncommon (Thompson \& Schuster, 1968).

Like Holtzman rats (Wnek \& Leaf, 1973), however, Long-Evans rats could not be induced to kill with repeated injections of arecoline. Pilocarpine seems to be ideosyncratic among peripherally injected cholinomimetic agents in that it can reliably induce mouse killing in rats. The mechanism by which pilocarpine induces killing is unclear, although it probably is due to some central action of the drug (Vogel \& Leaf, 1972; Wnek \& Leaf, 1973). Wnek and Leaf (1973) have suggested that the gradual nature of the phenomenon is due to the mixed central and peripheral actions of the drug. The peripheral autonomic effects are inhibitory (Gay, Leaf, \& Arble, 1975 ) and the animal may need to "learn" to overcome them in order for the central facilitatory actions to be expressed in behavior. This hypothesis is supported by the Long-Evans data which show rapid initiation of killing in this strain, which has a relatively low incidence of peripheral side effects.

It also seems unlikely that pilocarpine initiates killing by producing a painful irritation at the site of injection. In a physiological saline solution, pilocarpine $\mathrm{HCl}$ acts as a weak acid. A solution of $7.5 \mathrm{mg} / \mathrm{cc}(.03 \mathrm{M})$ has a $\mathrm{pH}$ of 4.40 , while solutions of 15 and $30 \mathrm{mg} / \mathrm{cc}$ are estimated to have a $\mathrm{pH}$ of approximately 4.25 and 4.10 , respectively. While the effective $\mathrm{pH}$ of this drug in the peritoneal cavity is unknown, it seems unlikely that the acidity of the drug accounts for its ability to initiate killing or its differential effectiveness compared to arecoline $\mathrm{HBr}$, which is nearly neutral in acqueous solution (Stecher. 1968). Rats, autopsied following $12-50+$ injections of $7.5 \mathrm{mg} / \mathrm{kg}$ pilocarpine, were not noted to show an abnormal incidence of lesions of the peritoneal cavity (Gay, Cole, \& Leaf, 1975). Moreover, two drugs which block killing (Vogel \& Leaf, 1972; Wnek \& Leaf, 1973), even when given repeatedly (Gay. Leaf, \& Arble, 1975), are also weak acids in acqueous solution (Stecher, 1968). d-Amphetamine $\mathrm{SO}_{4}$ and atropine $\mathrm{SO}_{4}$, at effective doses. have a $\mathrm{pH}$ between 5 and 6 (Stecher, 1968).

Isolation and sex were "weak" variables in these studies, perhaps because they interacted with strain and other factors [e.g., adaptation to mouse odors (Avis \& Treadway, 1971)]. Holtzman rats seemed to show a larger sex difference in pilocarpine-induced killing than did Long-Evans rats, even though a strong sex difference is evidenced in "spontaneous" Long-Evans killers (Myer, 1971). The nonsignificant isolation effect seemed stronger in animals with lower killing rates (females and Long-Evans males) than in animals with higher killing rates (Holtzman males).

\section{REFERENCES NOTES}

1. Gay, P. E., Cole, S. O., \& Leaf, R. C. Interactions of amygdala lesions with effects of pilocarpine and d-amphetamine on mouse-killing, feeding and drinking. Submitted for publication, 1975.

2. Gay, P. E., \& Leaf, R. C. The effects of d-amphetamine on prey-killing and prey-eating in the rat. Paper presented before the Eastern Psychological Association, April 1974.

\section{REFERENCES}

Avis, H. H., \& Treadway, J. T. Mediation of rat-moúse interspecific aggression by cage odor. Psychonomic Science, 1971, 22. $293-294$

Galef, B. G. Aggression and timidity: Responses to novelty in feral Norway rats. Journal of Comparative and Physiological Psychology, 1970, 70, 370-381.

GAY, P. E. Inhibitory effects of pre-and post-test d-amphetamine on mouse killing by rats. Unpublished doctoral dissertation, Rutgers University, 1973.

Gay, P. E., Leaf, R. C., \& Arble, F. B. Inhibitory effects of pre- and posttest drugs on mouse-killing by rats. Pharmacology, Biochemistry, and Behavior, 1975, 3. 33-45.

KarLI, P. The Norway rat's killing response to the white mouse. An experimental analysis. Bheaviour, 1956, 10, 81-103.

KarLI, P., Vergnes, M., \& Didiergeorges, F. Rat-mouse interspecific aggressive behaviour and its manipulation by brain ablations and by brain stimulation. In $S$. Garattini \& E. B. Sigg (Eds.), Aggressive behaviour. Amsterdam: Excerpta Medica Foundation, 1969. Pp. 47-55.

Lathan, E. E., \& Thorne, B. M. Septal damage and muricide: Effects of strain and handling. Physiology and Behavior, 1974, 12, 521-526.

McCarthy, D. Mouse-killing in rats treated with pilocarpine. Federation Proceedings, 1966, 25, 385. 
MYER, J. S. Experience and the stability of mouse-killing by rats. Journal of Comparative and Physiological Psychology, 1971, 75, 264-268.

Overstreet, D. H., Hadick, D. G., \& Russell, R. W. Effects of amphetamine and pilocarpine on eating behavior in rats with chronically low acetylcholinesterase levels. Behavioral Biology, 1972, 7, 217-226.

STECHER, P. G. (Ed.) The Merck index. Rahway: Merck \& Co., 1968.

Thompson, T., \& Schuster, C. R. Behavioral pharmacology. Englewood Cliffs, N.J: Prentice-Hall, 1968.

Ueki, S., Fujuvara, M., \& Ogawa, N. Mouse-killing behavior (muricide) induced by delta'-tetrahydrocannabinol in the rat. Physiology and Behavior, 1972, 9, 585-587.
Valzelli, L., \& Bernasconi, S. Differential activity of some psychotropic drugs as a function of emotional level in animals. Psychopharmacologia (Berlin), 1971, 21, 91-96.

VOGEL, J. R., \& LEAF, R. C. Initiation of mouse killing in non-killer rats by repeated pilocarpine treatment. Physiology and Behavior, 1972, 8, 421-424.

WNEK, D. J., \& LEAF, R. C. Effects of cholinergic drugs on prey-killing by rodents. Physiology and Behavior, 1973, 10, 1107-1113.

(Received for publication June 17, 1975; revision received July 28,1975 .) 